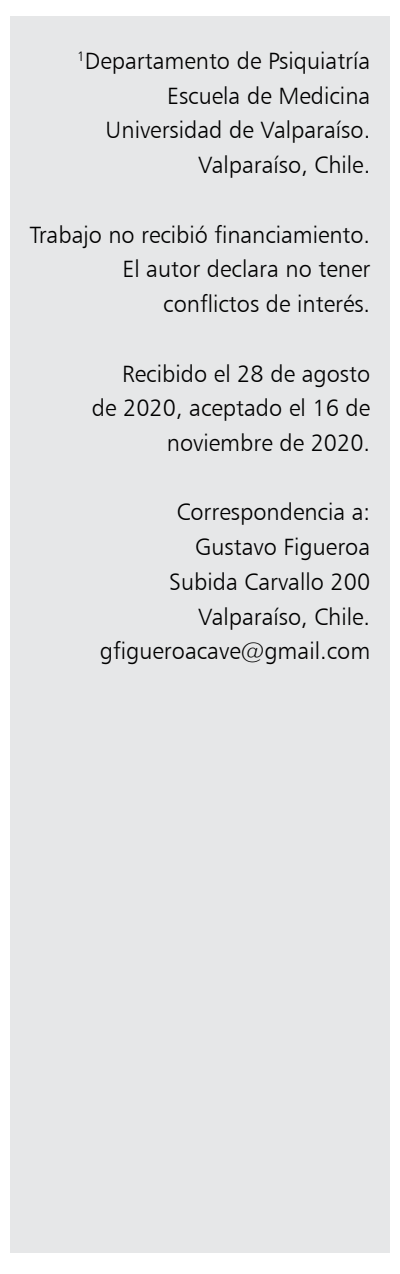

\section{Tribulaciones éticas del COVID-19: lo sobrecogedor siniestro, la responsabilidad existencial y Medice, Cura Te Ipsum}

\author{
GUSTAVO FIGUEROA ${ }^{1}$
}

Ethical tribulations of COVID-19: the sinister ominous, existential responsibility and Medice, Cura Te Ipsum

The COVID-19 pandemic revealed the vulnerability of the human being in their existential and medical fields. A feeling of uncertainty of an overwhelming and ominous nature indicates that dying is inherent for the human condition, a feeling that is daily hidden behind the mask of a casual, unexpected, random event. The possibility of dying from the viral disease revealed that the essence of man as being-in-the-world is ethical or self-assumption and is expressed through an original rather than a moral conscience, which calls for authenticity, to listen to its nihility as being-referred-to-death. The medical ethical principles based on rights and duties need to be perfected by the ethics of virtues in accordance with the current challenges, requiring a transformation of the moral self of the doctor. A moral failure of duty is inevitable for medicine, it will never reach its final realization.

(Rev Med Chile 2020; 148: 1668-1673)

Key words: Bioethics; Ego; Guilt.

\begin{abstract}
I
a irrupción del COVID-19 ha estremecido a la actual civilización de manera insospe$\checkmark$ chada y, aunque la historia está sembrada de epidemias desde tiempos remotos ${ }^{1}$, esta ha adquirido atributos especiales sin encontrar todavía respuestas validadas. Fiel a su tradición milenaria, la medicina se involucró desde sus inicios con solicitud, diferentes grados de efectividad y estimulando la cooperación internacional ${ }^{2}$. La bioética ha emitido numerosas propuestas según los ámbitos involucrados, toma de decisiones clínicas ${ }^{3}$, apoyo psicológico a portadores y cuidadores de salud $d^{4,5}$, guías de procedimiento para distintos países ${ }^{6}$ y situaciones extremas ${ }^{7}$, investigación clínica ${ }^{8}$ Inesperadamente, una atmósfera de incertidumbre envolvió la pandemia haciendo patente una vulnerabilidad profunda y oculta, que
\end{abstract}

contagió a la medicina en sus niveles personales, profesionales, sociales y científicos. Vulnerabilidad penetrante porque parece apuntar a comprometer sus fundamentos últimos y, de ser así, lo que significa enfermar, restablecerse y morir como ser humano. El presente estudio postula que la afección, más allá de estragos deletéreos de inusitada intensidad, ha involucrado estratos básicos tanto de la existencia como de la profesión, por ello se divide en tres partes: la inquietante extrañeza de nuestra condición, la culpa inherente a la persona y el cuidado propio del ser médico.

\section{Lo sobrecogedor siniestro}

De manera vertiginosa se instauró una transformación del ambiente tornándose inquietante, 
o, cuando menos, inusual, extraño, desasosegador. En contraposición a lo acostumbrado porque, aunque surjan problemas, contratiempos e incertezas, cotidianamente vivimos con el sentimiento profundo y envolvente de familiaridad, confianza, habitualidad. Por ello, Husserl habló de la "fe ciega" (Urglaube) en el mundo en el cual vivimos, y que ese es nuestro ámbito tradicional o mundode-la-vida9 . Blankenburg apuntó a la sensación de lo-evidente-de-suyo y natural (Selbstverständlichkeit) con que llevamos a cabo nuestra vida usual, amparados y absorbidos en aquello de lo que nos ocupamos -escribir, leer, jugar-, moviéndonos en la consagrada tradición de lo siempre-ya-sabido ${ }^{10}$.

Freud se preguntó si tras esta familiaridad se ocultaba algo, porque sus pacientes experimentaban sensaciones del orden del displacer desasosegante cuyo origen les era totalmente desconocido y que, tras acuciosos análisis, revelaban una angustia ante peligros-peligros internos-reprimidos anteriormente. De ahí su pregunta ¿existe una relación entre lo familiar, ansiedad ante lo interior oculto y lo inquietante? Si fuera así ¿cómo es posible que lo familiar, lo consabido desde antiguo devenga lo opuesto, ominoso, siniestro? Das Unheimliche ${ }^{11}$ es la respuesta de Freud: es lo opuesto de heimlich (íntimo), heimisch (doméstico), heimelich (familiar o perteneciente al hogar), heimlich (confiable, propio de la entrañable intimidad del terruño). Esta palabra heimlich no es unívoca, sino abarca dos campos pragmáticos contrapuestos: el de lo familiar y agradable y el de lo clandestino que permanece secreto, enigmático. Lo ominoso proviene del latín ominosus, que a su vez desciende de omen, esto es presagio, abominable, y siniestro del latín sinister, maligno, de mal agüero. Con el prefijo negativo "un- "sucede un equívoco similar que con el vocablo inglés un-canny: canny es tanto confortable (cosy) como dotado con un poder mágico u oculto. Para Freud no cabe duda: lo siniestro es lo familiar-entrañable (íntimo-hogareño) a la vida psíquica, que se trasmuta en ajeno motivado por una represión y que, posteriormente, retorna desde ella: "Lo siniestro del vivenciar se produce cuando unos complejos infantiles reprimidos son reanimados por una impresión, o cuando parecen ser reafirmadas unas convicciones primitivas superadas". Son las pulsiones más arcaicas las que reviven inesperadamente, las sexuales fundidas inextricablemente con las agresivas o tanáticas: nuestro primer contacto con la realidad. Bion ${ }^{12}$ señala que, al momento de nacer, los datos sensoriales crudos, expresión inmediata de nuestras pulsiones destructivas más originarias, constituyen una ansiedad extrema o terror sin nombre (nameless dread) no solamente por carecer de significado; son absolutamente intolerables porque, careciendo de una matriz psicológica estructurante primigenia, no pueden otorgárseles un sentido. Es la madre la encargada de metabolizar lo innominado, aterrorizante, devolviéndoselo con una significación, vale decir, representaciones mentales con sentido; pero simultáneamente, expulsando en el exterior el pavor tanático interno. Hasta aquí lo óntico.

Ortega y Gasset ${ }^{13}$ señaló que nuestro habitar es un permanente pero inalcanzable afán por morar, un esforzarse por algo(gewinnen), un aspirar a algo que nos falta(wunsch) pero es inseguro, impredecible, esperado (wahn) pero no alcanzado, porque la tierra es para el hombre inhabitable, extraña, impropia. Heidegger partió del primer canto de "Antígona" de Sófocles: "Muchas cosas son pavorosas; / nada, sin embargo, sobrepasa al hombre en pavor"(332-334) $)^{14}$. "Lo más pavoroso" corresponde al griego tó deinoterón, en alemán unheimlich, que como vimos es lo in-hóspito, desazonante, lo terrible, que somete y se impone furiosamente, imperando por la violencia ${ }^{15}$. Heidegger enfatiza que Sófocles mostró que el ser humano no solo vive en medio de lo pavoroso, siniestro, o ejecuta actos violentos como ningún animal lo hace, sino que su esencia radica en ser la violencia de lo pavoroso: "a él le alcanza la ruina, la desgracia, y en tanto que todos los caminos carecen de salida, se ve arrojado fuera de cualquier relación con lo familiar (heimlich)". Lo pavoroso-la violencia del poeta Sófocles-es la primera visión histórica de la finitud propia, constitutiva de lo humano, su no-ser último que metafísicamente se denomina facticidad o estado-de-arrojado ${ }^{16}$. El ser humano es ser-en-el-mundo, o sea, "existencia" (proyecto-lanzado-de-ser), "caida” (Verfallenheit) (comprenderse-desde-aquello-que-nos-ocupa) y "facticidad" (estar-arrojado-ya en un mundo que precede-y-se-está-implantado). Vale decir, 1] libres para autoelegirnos; 2] no-libres radicalmente, nunca nuestro propio fundamento, jamás dueños incondicionados del propio ser; 3] esta carencia-de-ser-primario la encubrimos fascinándonos con las novedades del mundo social, habladurías de-la-gente, o impersonal "se" ("se" dice, "se" 
afirma $)^{17}$. Esta carencia-de-fundamento-de-ser constituye nuestra radical finitud: basamento de todo proyecto, negatividad insuperable, no-ser ineludible, en concreto, la muerte, el morir inherente a nuestra condición.

En el plano óntico, Freud mostró que lo reprimido originario es el terror sin nombre del horror asesino interno-thánatos-, que solo se puede manejar expeliéndolo al mundo externo. En el ontológico, Ortega y Gasset y Heidegger señalan que lo originario es lo inhóspito, la finitud, la nihilidad, consustancial ser-referido-a-la-muerte; esto es, nunca se ponen las posibilidades ex novo y ex origene, sino que se está-ya-puesto en ellas por ser finitud o no-ser, jamás propietario del fundamento ${ }^{18}$. La actual incertidumbre desasonante y ominosa del COVID-19 de-veló, des-cubrió, trajo-a-presencia nuestra sustancia primera oculta, nuestra manquedad ontológica: no solo "se" muere, sino que se "es" ser-referido-al-morir.

\section{La responsabilidad existencial}

Si la pandemia des-ocultó lo más propio e insoslayable de nuestra esencia-"ser" mortal-, surge la pregunta ¿qué es morir para el ser humano? El morir es un hecho, un dejar de vivir (ableben), un estar-al-final ( $\mathrm{Zu}$-Ende-sein) específico de nuestra naturaleza biológica, tan aprehensible como la digestión, mitosis, meiosis. Aristóteles sentó las bases al determinar nuestra entidad como zóon lógon ékhôn, animal dotado de razón y esta "animalidad" impera de manera absoluta ${ }^{19}$.

La medicina desentraña el morir utilizando el método científico, sometiéndolo a investigación (Forschung), esto es, circunscribiendo por anticipado "un" campo delimitado; como proyecto-previo (Vorentwurf) pre-determina el saber, y encuentra como objeto solamente lo que "su" tipo de representación ha admitido con anterioridad ${ }^{20}$. Este proceder es un tipo de pensar, el calculador (Verrechnen), que da prioridad a la actitud objetivadora, dominadora, instrumental, clasificatoria. "La realidad" (Wirklichkeit) médica proviene del producir (wirken), de un "proceder ejecutivo-asegurador" en que lo hecho-presente (An-wesen)-el morir-es un resultado (Er-gebnis); este efecto (Er-folg) decretado por el accionar del investigador es lo ob-jetivo.

Heidegger pone en guardia: la ob-jetividad no es sino "una" de las maneras posibles de hacerse presente la realidad, pero no la incondicional y, sobre todo, no la fundamental sino colateral y, si se restringe exclusivamente a ella, desfiguradora de lo que aparece, aún aniquiladora (Vernichtung), especialmente cuando se refiere al hombre ${ }^{21}$. Lo "objetivo" del morir no considera suficientemente que es "una" posibilidad y, si es así, omite lo decisivo: el ser humano "es" sus posibilidades y no solo "tiene" posibilidades porque su vivir es proyecto (Entwurf), anticiparse-a-sí como posibilidad. Tarea contradictoria porque su facticidad, según vimos, quiere decir que sus posibilidades no siempre las pone él, que está-ya-arrojado entre posibilidades y realidades que él ni las ha producido ni controlado por completo y, a pesar de ello, tiene-que-hacerse-cargo de estas, pero ahora más radicalmente, porque se trata de su posibilidad última, inevitable e intransferible ${ }^{22}$. Tiene-que $(z u-$ sein) eludirla o escogerla. Si la elude, el morir es un acontecimiento como cualquiera, casual, fortuito, imprevisto. Si es una autoelección (Selbstwahl), la muerte no solo es su posiblidad insuperable, sino más propia (eigen) porque asume lo que nadie sino él puede apoderarse o apropiarse. La apropiación (Eigentlichkeit) le patentiza que el morir no es estar-al-final sino, contrariamente, lo que él "es": un ser-referido-al-final (ein-zum-Ende). Proyectándose desde el futuro, el final -morir- se desnuda como lo opuesto a lo que cotidianamente se supone, como la esencia de su existencia ${ }^{23}$.

Hasta aquí señalamos que la pandemia situó a la muerte bajo una doble óptica. Por un lado, como un sentimiento sobrecogedor ominoso y, por otro, como acontecimiento fortuito, azaroso, inesperado. Indicamos que en ambos casos desaparece el morir como posibilidad-de-ser, manifestándose solo como factum, hecho constatable empíricamente. Pero es "la" posibilidad humana decisiva porque este "es" ser-para-lamuerte (Sein-zum-Tode), por tanto, cabe evadirla o asumirla ${ }^{24}$. Ante los dilemas éticos, el enfermo, moribundo, médico, requieren elegir el curso óptimo y desde Aristóteles se habla de la necesidad previa de euboulía o buena deliberación ${ }^{25}$. Sin embargo, estamos en un plano ontológico y no óntico, no se trata de la deliberación propia de la ciencia, política, sociología, sino de la ex-sistencia. Se apuntó que nuestra carencia-de-ser procede que nuestro fundamento nunca ha sido propio; esta negatividad, déficit, falla radical no es una 
falta cometida en la vida sino hemos sido-arrojado-ya-en-falta respecto al origen de nuestro ser. Mientras la primera se rectifica corrigiendo el daño que se cometió mediante una acción, la segunda define nuestra condición original. Diferente al sentido-de-su-hacer se alza el sentido-de-su-ser, opuesto al estar-en-deuda emerge el ser-deudor ${ }^{26}$. Así coexisten dos modos de "mala conciencia" (Gewissen): moral o derivada y la existencial u originaria; la que cuestiona las faltas concretas y la que observa al fondo de sí-mismo, a la esencia de su negatividad. Y las dos se expresan en una llamada $(R u f)$, pero esta llamada concierne a cuestiones radicalmente diferentes. La conciencia moral se determina-a-si como "sujeto", auto-desdoblándose en una voz objetivante que se hace-presente-a-sí-misma como "tribunal": compara críticamente su conducta con una medida objetiva ideal "en la dimensión del «calcular» según el «debe» y el «haber»". Contrariamente, la conciencia existencial ni juzga ni condena, solo entrega un testimonio irrefutable de su más auténtica posibilidad: ser-para-la-muerte (Seinzum-Tode); esta posibilidad-de-la-imposibildad es la resolución-anticipadora (Entschlossenheit), rescatarse de su estar-absorbido-por-el-mundo-cotidiano-im-propio hacia un afrontar sin máscaras su facticidad-propia ${ }^{27}$.

La pandemia ha evidenciado la doble voz y doble responsabilidad de nuestro ser ante el morir: calcular, deber, actuar, y asumirse, apropiarse, serenidad o desasimiento (Gelassenheit) ${ }^{28}$.

\section{Medice, cura te ipsum}

La pandemia reavivó los problemas éticos inmanentes a la medicina desde sus albores, aunque trasformados por desplegarse en una sociedad dominada por la biopolítica, medicalización y normalización o regulación de los sujetos según la media ${ }^{29}$. "Ser médico" con ocasión del COVID-19 ¿requirió una ética tradicional, una actual o una original?

1] La medicina nació en Grecia como una de las tres profesiones como se expresa en el Juramento: el médico es un profeso. Professio latino procede de fassio y del verbo profiteor que significa confesar públicamente, proclamar y esta confesión es una promesa solemne o consagración que lo convierte en profesional. Este tinte religioso se mantuvo en el tiempo, reflejándose en el período de iniciación que se inaugura con una fórmula juramental, comprometiéndose a observar solemnemente una serie de normas, reglas. Dos atributos profesionales fueron puestos a prueba ante la posibilidad real de morir por el virus. A] Ser médico es una trasformación, adquirir un "modo de vida" específico, el bíos iatrikós, esto es, no solo saber qué es la enfermedad sino un actuar-praxis-,que conlleva una actitud o hábito (ethos) y los hábitos repetidos se convierten en virtudes. El médico que busca el bien de sus enfermos es el médico virtuoso, el que posee areté o virtud, que designa al "médico excelente" y la excelencia es la meta de su proceder. Empero hay que diferenciar dos modos de entender la virtud: la condición moral positiva y la capacidad de ejecutar algo bien: médico bueno y buen médico. El médico excelente es aquel que posee la areté propia de la profesión en sus dos vertientes ${ }^{30}$. El COVID-19 ha exigido al médico en ambos flancos, pero reveló lo que MacIntyre recalcaba enérgicamente. La ética de la virtud de la antigüedad ha sido reemplazada por la ética de los derechos y deberes de la Ilustración y, por ello, estamos en una época "después de la virtud" (after virtue), por lo que se requiere ir "tras la virtud" 31 . Los médicos de la pandemia la han ejecutado efectivamente: se han entregado mucho más allá de los derechos y deberes, han ejercido su quehacer siguiendo las virtudes de fortaleza (andreía), prudencia (phrónesis), moderación (sophrosyné), justicia (dikaiosyne). B] Weber expuso que la profesión es una elección de valor, un proyecto de ser leal a los valores que al profesional se le imponen por estar necesitados de realización ${ }^{32}$. Así la palabra alemana profesión (Beruf) está emparentada con llamada (Ruf), con la "voz" interna que invoca y apela, con la "vocación": vocación es misión, acometer aquello a lo que su intimidad auténtica lo impele, llamada a comprometerse con su proyecto vital. Es una ética de la responsabilidad (Verantwortung) consigo que sigue el mandamiento de Píndaro "llega a ser el que eres"33. El equipo médico COVID-19 ha renovado el perfil de aspiraciones, anhelos, mandatos de su misión: hacerlos reales, genuinos, mejor aún, insuflarles vitalidad existencial.

2] Medice, cura te ipsum ${ }^{34}$ según Hipócrates: "las relaciones entre el médico y sus pacientes no son algo de poca monta...; la mayoría de la gente opina que quienes no tienen su cuerpo en buenas condiciones no cuidan bien de los aje- 
nos"35. Foucault señaló que cura, souci, expresa el cuidado-de-sí-mismo, la moral ejercida sobre sí-mismo, el constituirse como sujeto moral, en nuestro caso, sí-mismo moral médica, esto es, trabajo preparatorio íntimo para encarar la realidad del enfermo y el morir ${ }^{36}$. Trabajo sobre sí-mismo doble $\left.{ }^{37}: \mathrm{a}\right]$ "conócete a ti mismo" (gnothi sauton), que Sócrates precisó como el saber del que no sabe de sí porque permanece oculto en su interior, que exige su desciframiento para ponerlo a su disposición; todo médico requirió conocerse para curarse de sus problemas personales no resueltos, sanarse de sus conflictos para poder ayudar a sus enfermos. b] Preocupación-por-sí-mismo (epiméleia heautóu) del médico, conminación más allá de reglamentos prescriptivos: ascesis, prácticas, ejercicios espirituales, meditaciones consigo dedicadas a volverse sobre sí-mismo transformando su intimidad, haciéndole competente para ejercer su misión de curar ${ }^{38}$.

\section{Perspectivas}

1. La pandemia COVID-19 ha revelado la vulnerabilidad oculta de nuestra condición humana en los dominios personales, sociales, políticos, expresada como incertidumbre ominosa ante lo desconocido y la muerte.

2. La medicina ha respondido a su misión en tres ámbitos: individual, profesional, comunitario.

3. La verdad del saber médico no solo es conocimiento sino una práctica, un ejercicio sobre la verdad del sí-mismo médico.

4. La ética médica precisó perfeccionar los derechos y deberes renovando creativamente la tradicional ética de las virtudes, que reivindica una transformación del sí-mismo moral del médico.

5. Existe un moral gap $p^{39}$ o fracaso moral inevitable del deber al que la medicina está constreñida, jamás alcanzará su realización definitiva.

6. Se cumplió un cuarto de siglo desde el nacimiento de la bioética ¿sigue siendo la Circe de la medicina? ${ }^{40}$

\section{Referencias}

1. McNeill WH. Plagues and peoples. New York: Anchor 1976.

2. Saxena SK, editor. Corona virus disease 2019 (CO-
VID-19). Epidemiology, pathogenesis, diagnosis, and therapeutics. Singapore: Springer 2020.

3. Valera L, Carrasco MA, López R, Ramos P, v Bernhardi R, Bedregal P, Florenzano A, et al. Orientaciones éticas para la toma de decisiones médicas en el contexto de la pandemia de COVID-19 en Chile. Rev Med Chile 2020; 148: 393-8.

4. Rauch SAM, Simon NM, Rothbaum BO. Phased Approach for Supporting the Mental Health of Healthcare Workers and Others Affected by the COVID-19 Pandemic (PAC). https://adaa.org/sites/default/files/ PhasedApproachtoCovid-19.ver1.1\%20(002).pdf.

5. Rauch SAM, Simon NM, Rothbaum BO. Rising tide: Responding to the mental health impact of the COVID-19 pandemic. Depress Anxiety 2020; 37: 505-9.

6. Huxtable R. COVID-19: where is the national ethical guidance? BMC Medical Ethics 2020; 21: 32.

7. Joebges S, Biller-Andorno N. Ethics guidelines on COVID-19 triage-an emerging international consensus. Critical Care 2020; 24: 201.

8. Meagher KM, Cummins NW, Bharucha AE, Badley AD, Chlan LL, Wright RS. COVID-19: Ethics and Research. Mayo Clin Proc 2020; 95 (6): 1119-23.

9. Husserl E. Die Krisis der europäischen Wissenschaften und die transzendentale Phänomenologie. Husserliana VI. Den Haag: Martinus Nijhoff 1962.

10. Blankenburg W. Der Verlust der natürlichen Selbstverständlichkeit. Ein Beitrag zur Psychopathologie symptomarmer Schizophrenien. Stuttgart: Enke 1971.

11. Freud S. Das Unheimliche. Gesammelte Werke XII. Frankfurt: Fischer 1919; 229-68.

12. Bion W. A theory of thinking. Int J Psycho-Anal 1962; 43: 306-10.

13. Ortega y Gasset J. Pasado y porvenir para el hombre actual. Obras Completas IX. Madrid: Revista de Occidente 1958; 613-747.

14. Sófocles. Tragedias. Madrid, Gredos 1981.

15. Heidegger M. Einführung in die Metaphysik. Gesamtausgabe 40. Frankfurt: Klostermann 1983.

16. Heidegger M. Ontologie (Hermeneutik der Faktizität). Gesamtausgabe 63. Frankfurt, Klostermann 1982.

17. Heidegger M. Sein und Zeit.10. Aufl. Tübingen, Niemeyer 1963.

18. Heidegger M. Kant und das Problem der Metaphysik. Gesamtausgabe 3. Frankfurt: Klostermann 2010.

19. Aristóteles. Metafísica. 2 volúmenes. Madrid: Gredos 1970.

20. Heidegger M. Wissenschaft und Besinnung. En: Vortäge und Aufsätze. 5.Aufl. Pfullingen: Neske 1967; 41-66.

21. Heidegger M. Das Ding. En: Vorträge und Aufsätze. 5. Aufl. Pfullingen: Neske 1967; 157-75. 
22. Heidegger M. Brief über den "Humanismus". Gesamtausgabe 9. Frankfurt: Klostermann 1976; 313-64.

23. Rodríguez R. La hermenéutica del sí mismo en Ser y Tiempo. En Brickle P, ed. La filosofía como pasión. Madrid: Trotta 2003; 53-68.

24. Heidegger M. Prolegomena zur Geschichte des Zeitbegriffes. Gesamtausgabe 20. Frankfurt: Klostermann 1979.

25. Gracia D. Teoría y práctica de la deliberación moral. En: Feito L, Gracia D, Sánchez M. (Editores). Madrid: Triacastela 2011; 101-52.

26. Figueroa G. La bioética actual: las interrogantes de Heidegger. Rev Med Chile 2011; 139: 1377-82.

27. Cerezo P. De la existencia ética a la ética originaria. En: Cerezo P, Duque F, Leyte A, Martínez Marzoa F, Peñalver P y Rodríguez R. Heidegger: la voz de tiempos sombríos. Barcelona: Ediciones del Serbal 1991; 11-79.

28. Heidegger M. Gelassenheit. 7. Auflage. Frankfurt: Neske 1982.

29. Foucault M. Naissance de la biopolitique. Cours au Collège de France (1978-1979). Paris: Seuil/Gallimard 2004.

30. Gracia D. Como arqueros al blanco. Estudios de bioética. Madrid: Triacastela 2004.
31. MacIntyre A. After virtue. $2^{\text {a }}$ ed. Notre Dame: University of Notre Dame 1984.

32. Weber M. Wissenschaft als Beruf/Politik als Beruf. Jubiläumsausgabe. Frankfurt: UTB GmbH 2020.

33. Ortega y Gasset J. Vives-Goethe. Obras completas IX. Madrid: Revista de Occidente 1958; 503-43.

34. Gracia D. Medice, cura te ipsum. Sobre la salud física y mental de los profeionales sanitarios. Madrid: Instituto de España, Real Academia Nacional de Medicina 2004.

35. Tratados hipocráticos I. Madrid: Gredos 1990.

36. Foucault M. Histoire de la sexualité 3. Le souci de soi. Paris: Gallimard 1984.

37. Foucault M. L'origine de l'herméneutique de soi. Conférences prononcées au Dartmouth College. Paris: Vrin 2013.

38. Foucault M. L'herméneutique du sujet. Cours au Collége de France. 1981-1982. Paris: Gallimard/Seuil 2001.

39. Hare JE. The moral gap: Kantian ethics, human limits, and God's assistance. Oxford: Clarendon Press 1996.

40. Figueroa G. Bioética ¿La Circe de la Medicina? Rev Med Chile 2001; 129: 209-17. 